\title{
ANALISIS KANDUNGAN LOGAM Fe DAN Mn ES BATU YANG ADA DI KECAMATAN ARUT SELATAN \\ KABUPATEN KOTAWARINGIN BARAT \\ DENGAN METODE SPEKTROFOMETRI \\ SERAPAN ATOM
}

\author{
Agustoni Pujianto ${ }^{1}$ Risa Wahyuningsih ${ }^{2}$ \\ ${ }^{12}$ STIKes Borneo CendekiaMedikaPangkalan Bun \\ ${ }^{1}$ Email :agustonipujianto33@gmail.com
}

\begin{abstract}
ABSTRAK
Telah dilakukan penelitian analisis kandungan logam Fe dan Mn pada es batu yang ada di Kecamatan Arut Selatan Kabupaten Kotawaringin Barat dengan Metode spektrofotometri serapan atom. Analisis kuantitatif dilakukan dengan mengukur kandungan logam $\mathrm{Fe}$ dan $\mathrm{Mn}$ pada es batu dengan metode spektrofometri serapan atom. Hasil penelitian menunjukkan bahwa 4 dari 14 sampel menunjukkan hasil positif mengandung logam $\mathrm{Fe}$ dan logam $\mathrm{Mn}$. Pada penetapan kadar logam $\mathrm{Fe}$ dengan panjang gelombang $248,3 \mathrm{~nm}$ yang terdeteksi pada sampel 5 sebesar 0,315 $\mathrm{mg} / \mathrm{l}$, sampel 9 sebesar 0,226 mg/l, sampel 11 sebesar 0,277 mg/l dan sampel 13 sebesar 0,121 mg/l. Untuk hasil kadar logam Mn dengan panjang gelombang 279,5 $\mathrm{nm}$ yang terdeteksi pada sampel 6 sebesar 0,611 mg/l, sampel 9 sampel 3,127 mg/l, sampel 13 sebesar 0,5981 mg/l dan sampel 14 sebesar0,4664 mg/l.
\end{abstract}

Kata kunci : Es Batu, Spektrofometri Serapan Atom, Fe, Mn

\section{ANALYSIS OF Fe AND Mn ES STONE METAL CONTENT IN SOUTH ARUT DISTRICTWEST KOTAWARINGIN DISTRICTWITH THE SPECTROFOMETRY METHODATOM ABSORPTION}

\begin{abstract}
An analysis of the Fe and Mn metal content of ice cubes in the Arut Selatan District of Kotawaringin Barat has been conducted with atomic absorption spectrophotometry method. Quantitative analysis is done by measuring the metal content of $\mathrm{Fe}$ and $\mathrm{Mn}$ in ice cubes by atomic absorption spectrophotometry. The results showed that 4 out of 14 samples showed positive results containing Fe metal and Mn metal. In the determination of Fe metal content with a wavelength of 248.3 $\mathrm{nm}$ detected in sample 5 was $0.315 \mathrm{mg} / \mathrm{l}$, sample 9 was $0.226 \mathrm{mg} / \mathrm{l}$, sample 11 was $0.277 \mathrm{mg} / \mathrm{l}$ and sample 13 was $0.121 \mathrm{mg} / \mathrm{l}$. For the results of Mn metal content with a wavelength of $279.5 \mathrm{~nm}$ detected in sample 6 was $0.611 \mathrm{mg} / \mathrm{l}$, sample 9 was $3.127 \mathrm{mg} / \mathrm{l}$, sample 13 was $0.5981 \mathrm{mg} / \mathrm{l}$ and sample $14 \mathrm{was} 0.4664 \mathrm{mg} / \mathrm{l}$.
\end{abstract}

Keywords: Ice Cubes, Atomic Absorption Spectropometry, Fe, Mn 


\section{Pendahuluan}

Air konsumsi adalah air yang memenuhi persyaratan sebagaimana ditetapkan Kepmenkes RI No. 907/MENKES/SK/VII/2002 tanggal 29 Juli 2002 tentang Syarat-syarat dan Pengawasan Kualitas Air Minum yaitu kadar Fe sebesar 0,3 mg/L. Secara kualitas, ditemukan beberapa penyimpangan terhadap parameter kualitas air bersih, baik kualitas fisik, kimia, biologi, ataupun radioaktif. Penurunan kualitas air diantaranya diakibatkan oleh adanya kandungan besi yangsudah ada pada tanah karena lapisan-lapisan tanah yang dilewati air mengandungunsur-unsur kimia tertentu, salah satunya adalah persenyawaan besi. Besi merupakan salah satu unsur pokok alamiah dalam kerak bumi. Keberadaan besidalam air tanah biasanya berhubungan dengan pelarutan batuan dan mineralterutama oksida, sulfida karbonat, dan silikat yang mengandung logam-logam tersebut (Depeks, 2002).

Salah satu sumber daya alam yang paling penting bagi hidup manusia adalah sumber daya air. Air merupakan kebutuhan pokok manusia sehari-hari, sehingga dapat dikatakan manusia tidak dapat hidup tanpa air. Oleh karena itu perlu dipelihara kualitasnya agar tetap bermanfaat bagi kehidupan manusia serta makhluk hidup lainnya. Diperkirakan dari tahun ke tahun kebutuhan akan air semakin meningkat, bukan hanya disebabkan oleh peningkatan jumlah penduduk akan tetapi disebabkan oleh kebutuhan per kapita yang meningkat sesuai dengan perkembangan pola hidup manusia (Mahida, 1986).

Pencemaran air yang disebabkan oleh komponen komponen anorganik dan organik yang berasal dari kegiatan manusia seperti industri maupun buangandomestikdiantaranya berbagai logam berat berbahaya.Beberapa logam tersebut banyak digunakan dalam berbagai keperluan, karena diproduksi secara rutin dalam skala industri.Penggunaan logam - logam berat tersebut ternyata langsung maupun tidak langsung telah mencemari lingkungan melebihi batas yang berbahaya jika ditemukan dalam konsentrasi tinggi dalam lingkungan, karena logam tersebut mempunyai sifat merusak tubuh makhluk hidup.

Kandungan $\mathrm{Fe}$ di bumi sekitar $6,22 \%$, di tanah sekitar $0,5-4,3 \%$, di sungai sekitar $0,7 \mathrm{mg} / \mathrm{L}$, di air tanah sekitar 0,1 - $10 \mathrm{mg} / \mathrm{L}$, air laut sekitar 1 - 3 ppb, pada air minum tidak lebih dari 200 ppm. Pada air permukaan biasanya kandungan zat besi relatif rendah yakni jarang melebihi $1 \mathrm{mg} / \mathrm{L}$ sedangkan konsentrasi besi pada air tanah bervariasi mulai dan $0,01 \mathrm{mg} / \mathrm{L}$ sampai dengan $+25 \mathrm{mg} / \mathrm{L}$. Kandungan Mn di bumi sekitar 1060 ppm, di tanah sekitar 61 - 1010 ppm, di sungai sekitar $7 \mathrm{mg} / \mathrm{L}$, di laut sekitar $10 \mathrm{ppm}$, di air tanah sekitar $<0.1 \mathrm{mg} / \mathrm{L}$.

Logam - logam tersebut diketahui dapat berada di dalam tubuh suatu organisme dan tetap tinggal dalam tubuh untuk jangka waktu yang lama sebagai racun yang terakumulasi. Telah diketahui bahwa persediaan air dari berbagai sumber air sangat terbatas dengan distribusi yang tidak merata, sehingga perlu dicari upaya-upaya untuk mengatasi kelangkaan air bagi generasi yang akan datang. Kelangkaan air akan merangsang pemanfaatan air dari berbagai sumber air. Dilihat dari parameter kualitas lingkungan, termasuk kualitas air memerlukan suatu pengetahuan dan pemahaman yang memadai tentang pengertian parameter kualitas lingkungan, keterkaiatan antara parameter, hubungan kausatif antar- 
parameter,peranan parameterparameter tersebut dalam keseimbangan lingkungan.(Effendi, 2003).

\section{METODE PENELITIAN}

Kategori penelitian yang dilakukan dalam penelitian ini adalah true experimental laboratories yang terdiri dari :

Tahap I:Pengumpulan sampel es batu Tahap II : Pengukuran kadar logam Fe dan $\mathrm{Mn}$

\section{Tahap 1 :}

1. Pengumpulan Sampel Uji

Dari sampel yang telah dikumpulkan, dilakukan pengambilan secara acak di berbagai tempat yang ada di daerah arut selatan. Sampel yang didapat sebanyak 14 sampel.

\section{Tahap 2 :}

1. Preparasi Sampel

Sampel es batu yang telah disiapkan dibiarkan hingga mencair, kemudian masing-masing sampel dipipet sebanyak $20 \mathrm{~mL}$ dan ditambahkan asam nitrat pekat sebanyak $2 \mathrm{~mL}$. Sampel kemudian dipanaskan diatas pemanas dengan temperatur $100^{\circ} \mathrm{C}$ sampai seperempat volume awal. Dinginkan dan masukan kedalam tabung selanjutnya ditambah aquadest sampai $10 \mathrm{~mL}$.

2. Pembuatan Larutan Standar

a. Pembuatan Larutan Standar Fe

Dipipet $10 \mathrm{~mL}$ larutan induk $\mathrm{Fe}$ $1000 \mathrm{mg} / \mathrm{L}$ dan dimasukkan ke dalam labu ukur $100 \mathrm{~mL}$, tepatkan dengan larutan pengencer sampai tanda tera. Dipipetmasing - masing 0,5 mL; $1 \mathrm{~mL}$; $1,5 \mathrm{~mL}$ dan $2 \mathrm{~mL}$ larutan dimasukkan masing - masing ke dalam labu ukur $100 \mathrm{~mL}$,diencerkan dengan aquabidest hingga garis tanda.

b. Pembuatan Larutan Standar Mn

Dipipet $10 \mathrm{~mL}$ larutan induk $\mathrm{Mn}$ $1000 \mathrm{mg} / \mathrm{L}$ dan dimasukkan ke dalam labu ukur $100 \mathrm{~mL}$, tepatkan dengan larutan pengencer sampai tanda tera.Dipipet masing - masing 0,5 mL; $1 \mathrm{~mL} ; 1,5 \mathrm{~mL}$, dan $2 \mathrm{~mL}$ larutan dimasukkan masing - masing ke dalam labu ukur $100 \mathrm{~mL}$, diencerkan dengan aquabidest hingga garis tanda.

3. Pembuatan Kurva

Pembuatan kurva dibuat dengan cara mengukur serapan larutan baku dari masing-masing logam (Fe dan $\mathrm{Mn}$ ) pada berbagai konsentrasi. Selanjutnya dari hasil pengukuran tersebut dibuat kurva dengan metode regresi linear, didapat persamaan $\mathrm{y}=\mathrm{a}+\mathrm{bx}$ dimana $\mathrm{x}$ sebagai konsentrasi dan y sebagai absorbansi

4. Pengukuran Kadar Logam dalam Sampel

Masing-masing sampel yang telah di preparasi dituangkan ke dalam tabung yang berbeda serta blanko. Burner dinyalakan serta tombol pengatur aliran sampel, setelah itu dibaca serapannya pada panjang gelombang $(\lambda)=248,3$ nm untuk analisis $\mathrm{Fe}$ dan untuk analisis Mn dengan panjang gelombang $(\lambda)=$ $279,5 \mathrm{~nm}$.

\section{HASIL DAN PEMBAHASAN}

Telah dilakukan penelitian analisis kandungan logam $\mathrm{Fe}$ dan $\mathrm{Mn}$ pada es batu yang ada di Kecamatan Arut Selatan Kabupaten Kotawaringin Barat dengan menggunakan metode spektrofotometri serapan atom. Penelitian ini bertujuan untuk mengetahui seberapa banyak kandungan logam $\mathrm{Fe}$ dan Mn pada es batu. Pada pembuatan es batu yang baik juga diperlukan proses yang benar pertama panaskan air yang akan dijadikan es batu sampai mendidih agar tidak ada bakteri pada air tersebut. Proses selanjutnya didinginkan baru kemudian dimasukkan kedalam 
kulkas/fresser selama 1 hari agar es batu terbentuk padatan.

Penelitian ini diawali dengan pemilihan sampel es batu secara acak (random sampling). Sampel yang digunakan sebanyak 14 sampel yang didapat dari berbagai tempat yang berbeda.

Pada sampel es batu yang digunakan setelah dilakukan wawancara dengan penjual es batu, sebagian menjawab es batu dibeli di warung atau toko, sebagian penjual ada juga yang membuat sendiri. Pada penjual yang membuat es batu sendiri menjawab es batu yang digunakan terlebih dahulu dimasak sebelum dipadatkan. Ada juga penjual yang tidak tahu air yang digunakan karena hanya membeli di toko atau warung. Jenis es batu yang kebanyakan dipakai adalah jenis es batu yang keruh daripada jenis es batu yang jernih. Es batu yang bersih dan sehat atau layak dikonsumsi itu adalah jenis es batu yang memiliki kualitas setara makanan, oleh karena itu pemilihan air sebagai bahan baku wajib diperhitungkan.

Tahap selanjutnya sampel yang akan diteliti dilakukan perlakuan pendahuluan yaitu dengan penambahan asam nitrat pekat. Tujuan dari pemberian asam nitrat pekat yaitu agar logam $\mathrm{Fe}$ dan $\mathrm{Mn}$ dapat terdeteksi sempurna oleh alat. Pemberian asam nitrat ini juga dapat mengurangi pengotor yang ada pada sampel air.

Sampel yang telah dilakukan perlakuan pendahuluan tersebut kemudian siap untuk ditentukan kadar logamnya. Pengukuran dimulai dengan kurva standar dari masing-masing logam. Pada logam $\mathrm{Fe}$ diukur pada panjang gelombang 248,3 $\mathrm{nm}$ dan pada logam Mn diukur dengan panjang gelombang 279,5 $\mathrm{nm}$.

Hasil dari kurva kalibrasi $\mathrm{Fe}$ diperoleh persamaan garis $\mathrm{y}=0,1165 \mathrm{x}+$
0,0119 dengan nilai $\mathrm{r}$ 0,999. Pada kurva kalibrasi Mn diperoleh persamaan garis $\mathrm{y}=0,1518 \mathrm{x}+0,0082$ dengan nilai $r$ 0,998. Dengan hasil kurva kalibrasi $\mathrm{Fe}$ dan $\mathrm{Mn}$, menunjukan persamaan garis yang baik.

Dari hasil uji presisi didapatkan nilai \%RSD Fe 0,006627\% dan \%RSD Mn 0,00004706\%. Ketelitian alat dapat dikatakan baik apabila nilai RSD kurang dari $11 \%$. Karena nilai dari logam Fe dan Mn jauh dibawah $11 \%$ maka spektrofotometri serapan atom yang digunakan mempunyai ketelitian yang sangat baik sehingga layak untuk digunakan dalam analisis es batu.

Dari hasil uji akurasi untuk logam berat $\mathrm{Fe}$ pada pengukuran 1 didapat nilai rata-rata sebesar $104,76 \%$ dan pada pengukuran 2 sebesar $104,71 \%$. Dari hasil uji akurasi untuk logam berat $\mathrm{Mn}$ pada pengukuran $1 \mathrm{di}$ dapat nilai rata-rata sebesar $95,33 \%$ dan pengukuran 2 sebesar $95,45 \%$. Untuk uji akurasi hasil ini menunjukan rata-rata dari logam $\mathrm{Fe}$ dan $\mathrm{Mn}$ masih masuk dalam range, karena uji akurasi antara $95 \%-105 \%$.

Batas deteksi untuk $\mathrm{Fe}$ adalah 0,06mg/L, penentuan dilakukan secara statistik melalui garis linier dari kurva kalibrasi. Pada sampel 5, 9, 11 dan 13 menujukan nilai positif karena $\mathrm{Fe}$ berada diatas batas deteksi, sisa sampel menunjukan nilai yang negatif dikarenakan konsentrasi kecil atau dibawah batas deteksi.

Batas deteksi untuk Mn adalah $0,1 \mathrm{mg} / \mathrm{L}$, penentuan dilakukan secara statistik melalui garis linier dari kurva kalibrasi. Pada sampel 6, 9, 13 dan 14 menujukan nilai positif karena $\mathrm{Mn}$ berada diatas batas deteksi, sisa sampel menunjukan nilai yang negatif dikarenakan konsentrasi kecil atau dibawah batas deteksi. 
Pada pengujian kadar Fe dan Mn menunjukan adanya nilai logam yang berbeda-beda pada setiap sampel yang diujikan. Pada kadar Fe dan Mn setelah dilakukan pembacaan pada alat spektrofotometer, sampel yang diujikan banyak yang tidak terdeteksi. Hal ini kemungkinan karena larutan standar yang digunakan untuk pengujian berbeda sehingga nilai kandungan $\mathrm{Fe}$ dan Mn pada sampel sangat kecil atau dibawah nilai standar batas deteksi. Untuk hasil uji kadar Fe, masih dapat dikatakan aman untuk dikonsumsi, untuk hasil uji kadar Mn tidak bisa dikatakan aman, karena sampel yang terdeteksi karena menurut SNI kadar es batu yang aman untuk kadar Fe dan Mn adalah $0,3 \mathrm{mg} / \mathrm{L}$ dan $0,1 \mathrm{mg} / \mathrm{L}$.

\section{KESIMPULAN DAN SARAN}

\section{Kesimpulan}

Hasil nilai kadar untuk logam berat $\mathrm{Fe}$ yang terdeteksi pada sampel 5 sebesar $0,315 \mathrm{mg} / \mathrm{L}$, sampel 9 sebesar 0,226 $\mathrm{mg} / \mathrm{L}$, sampel 11 sebesar 0,277 mg/Ldan sampel 13 sebesar 0,121 $\mathrm{mg} / \mathrm{L}$. Untuk hasil kadar logam berat Mn yang terdeteksi pada sampel 6 sebesar $0,611 \mathrm{mg} / \mathrm{L}$, sampel 9 sebesar 3,127 mg/L, sampel 13 sebesar 0,5981 $\mathrm{mg} / \mathrm{L}$ dan sampel 14 sebesar 0,4664 $\mathrm{mg} / \mathrm{L}$.

Menurut Standar Nasional Indonesia (SNI) es batu, standar mutu air minum yang dipersyaratkan baik dikonsumsi untuk $\mathrm{Fe}$ adalah $0,3 \mathrm{mg} / \mathrm{L}$ dan $\mathrm{Mn} \quad 0,1 \mathrm{mg} / \mathrm{L}$. Hasil ini menunjukan nilai kadar Fe masih aman untuk dikonsumsi karena tidak melebihi persyaratan SNI, tetapi untuk nilai kadar Mn hasil didapat melebihi dari persyaratan yang ditetapkan.

\section{Saran}

Perlu dilakukan penelitian kandungan logam berat yang lain karena es batu banyak dikonsumsi masyarakat. Pada proses pembuatan es batu lebih baik air yang digunakan untuk membuat es batu dimasak terlebih dahulu.

\section{DAFTAR PUSTAKA}

Depkes RI, 2002, “'Keputusan Mentri Kesehatan RI No 907/Menkes/Sk/VII/2002 tentang Syarat-Syarat dan Pengawasan Kualitas Air Minum', Depkes RI, Hlm. 5-15.

Mahida., U.N., 1986, "Pencemaran Air dan Pemanfaaatan Limbah Industri”, Gajah Mada UniversityPress, Jakarta, Hlm. 104-105.

Effendi., H. 2003, "Telaah Kualitas Air", Cetakan I, Penerbit Konisius, Yogyakarta, Hlm. 49-50 